\title{
Economic Impact of Fluopyram-Amended Seed Treatments to Reduce Soybean Yield Loss Associated with Sudden Death Syndrome
}

\author{
Amy M. Baetsen-Young, ${ }^{1, \dagger}$ Scott M. Swinton, ${ }^{2}$ and Martin I. Chilvers ${ }^{3}$ \\ ${ }^{1}$ Plant Resilience Institute, Department of Plant, Soil and Microbial Sciences, Michigan State University, East Lansing, MI \\ 48824, U.S.A. \\ ${ }^{2}$ Department of Agricultural, Food, and Resource Economics, Michigan State University, East Lansing, MI 48824, U.S.A. \\ ${ }^{3}$ Department of Plant, Soil and Microbial Sciences, Michigan State University, East Lansing, MI 48824, U.S.A.
}

\begin{abstract}
Soybean (Glycine max) sudden death syndrome (SDS), caused by Fusarium virguliforme, is a key limitation in reaching soybean yield potential, stemming from incomplete disease management through cultural practices and partial host resistance. A fungicidal seed treatment was released in 2014 with the active ingredient fluopyram and was the first chemical management strategy to reduce soybean yield loss stemming from SDS. Although farm level studies have found fluopyram profitable, we were curious to discover whether fluopyram would be beneficial nationally if targeted to soybean fields at risk for SDS yield loss. To estimate eco-

from 2018 to 2032. Through this framework of logistic adoption of fluopyram for alleviation of SDS-associated yield losses, we projected a net benefit of $\$ 5.8$ billion over 15 years, considering the costs of public seed treatment research and future extension communication. Although the sensitivity analysis indicates that overall net benefits from fluopyram adoption on SDS at-risk acres are highly dependent upon the market price of soybean, the incidence of SDS, the adoption path, and ceiling of this seed treatment, the net benefits still exceeded $\$ 407$ million in the worstcase scenario.
\end{abstract} nomic benefits of fluopyram adoption in SDS at-risk acres, in the light of U.S. public research and outreach from a privately developed product, we applied an economic surplus approach, calculating ex ante net benefits
Keywords: economic, fluopyram, Fusarium virguliforme, seed treatment, soybean, sudden death syndrome
Soybean (Glycine max L. Merrill) sudden death syndrome (SDS) is an economically damaging disease in the United States (Allen et al. 2017; Koenning and Wrather 2010). Since the first report in the 1970s in Arkansas, soybean SDS has quickly spread to nearly all soybean-producing states. In North America, soybean SDS is predominantly caused by the soilborne fungus Fusarium virguliforme O'Donnell \& T. Aoki (O'Donnell et al. 2010). F. virguliforme is an asexual hemibiotrophic fungus, infesting soil and crop residues. This fungus infects soybean roots during the early plant developmental stages (Jin et al. 1996), colonizing the xylem tissues, where the pathogen secretes phytotoxins, initiating programmed cell death of the soybean leaf (Brar and Bhattacharyya 2012). The host response creates the characteristic symptom of interveinal leaf scorch associated with SDS. Root infection and leaf scorch lead to a reduction of overall plant biomass and flowering, pod loss, and, thus, yield. Yield losses of up to $80 \%$ have been reported in highly infested fields but typically yield losses of 5 to $15 \%$ are observed (Hershman 2003; Roy et al. 1997).

Currently, no strategy can fully manage SDS. Partial genetic resistance of soybean cultivars has been developed through quantitative

\footnotetext{
${ }^{\dagger}$ Corresponding author: A. M. Baetsen-Young; abaetsen@gmail.com
}

Funding: Support for this research was provided by Michigan State University (MSU) project GREEEN grant number RA100463, MSU Plant Resilience Institute grant number GR100125-BEAN2; C.S. Mott Foundation grant number RT082734; and MSU AgBioResearch and the United States Department of Agriculture-National Institute of Food and Agriculture grant number MICL02575.

*The $\boldsymbol{e}$-Xtra logo stands for "electronic extra" and indicates that a supplementary table and supplementary file are published online.

The author(s) declare no conflict of interest.

Accepted for publication 8 July 2020.

(C) 2021 The American Phytopathological Society trait loci. However, if disease pressure is high in soybean fields, the partial resistance is broken (Njiti et al. 1996). Conditions inducing high disease pressure are thought to be cool temperatures and wet, compacted soil conditions during planting and early developmental stages (Chong et al. 2005; Roy et al. 1997; Rupe 1989; Scherm and Yang 1999). Tillage is thought to reduce symptom development by decreasing soil moisture and increasing soil temperature (Roy et al. 1997; Vick et al. 2006). An additional strategy for field crop disease management is crop rotation, which reduces pathogen population within soils by planting nonhosts for multiple years (Agrios 2004). Previous research on corn (Zea mays L.), soybean, and wheat (Triticum aestivum L.) rotation was found to reduce SDS yield losses when compared with continuous soybean (Roy et al. 1997; Von Qualen et al. 1989). However, more recent studies have shown that corn and other crop rotations have not reduced SDS severity (Hershman 2003; Leandro et al. 2018; Xing and Westphal 2009).

Because cultural approaches and limited genetic resistance have not consistently mitigated SDS-associated yield loss, a fungicidal seed treatment was released in 2014 with the active ingredient fluopyram, commercially designated as ILEVO (BASF, Research Triangle Park, NC, U.S.A.). Fluopyram is a succinate dehydrogenase inhibitor (SDHI) and was the first chemical management strategy to reduce soybean foliar symptoms and improve yields under SDS pressure in comparison with preexisting commercial base seed treatments of insecticide, fungicide, and nematicide (Gaspar et al. 2017; Kandel et al. 2016, 2018a,b, 2019b). These reported yield gains have ranged from 2.8 to $12.0 \%$ in fields with a historical SDS pressure. However, the cost of planting seed treated with fluopyram is also elevated, potentially reducing economic gains for growers. Thus, the profitability of the fluopyram seed treatment and probability of a positive return on investment have been explored, revealing an increasing probability of capturing return on investment with increasing disease pressure; however, profitability decreased with increasing seed costs (Kandel et al. 2018a) or decreasing grain sale price (Gaspar et al. 2017).

Previous studies have also compared costs and benefits of seed treatments of fungicide, insecticide, and nematicide activity against 
a commercial base or untreated controls (Gaspar et al. 2017; Kandel et al. 2018a; Rossman et al. 2018). As with the exploration of fluopyram, these analyses focused on the farm level, calculating profitability and return on investment with fixed soybean prices and quantities. Interestingly, Kandel et al. (2018a) assessed the impacts of fluopyram seed treatments upon soybean yield under SDS pressure across 200 field trials in 12 U.S. states. From these trials, a meta-analysis was conducted that found a $7.6 \%$ yield increase across the U.S. soybean production region. The parameterization of fluopyram yield benefits under SDS disease pressure across soybean production could enable the aggregate estimation of economic benefits to growers at risk for SDS-associated yield losses.

Previous research into national economic impacts of agricultural damage agents has dealt primarily with insect pests. The ease of scouting insects enabled the development of economic thresholds for management decision making (Stern et al. 1959). Economic evaluations of aggregate returns to public research from the use of insect integrated pest management (IPM) economic thresholds for field crop growers have found favorable returns (Greene et al. 1985; Musser et al. 1981; Norton and Mullen 1994; Song and Swinton 2009). Yet, although an increasing proportion of agricultural research and development occurs within the private sector (Alston et al. 1998b, 2009; Wang et al. 2013), the economic returns to publicly funded validation research have not been explored. We propose to contribute a plant disease study to evaluate the economic impact of a privately developed prophylactic application of fluopyram seed treatments as a disease management tactic for SDS.

\section{Materials and Methods}

Economic conceptual framework. An economic surplus approach modeled after Alston et al. (1998a) was applied to project the economic impact of SDS fluopyram research. The widespread adoption of SDS controls may cause changes in soybean quantities that affect traded market prices; therefore, the management tactic was evaluated as part of U.S. national soybean production. Changes in total economic surplus were computed from effects on revenues above costs for soybean producers (producer surplus) and the willingness to pay off consumers above the initial equilibrium price (consumer surplus). Because soybean crops are largely fed to livestock, price changes will ultimately affect consumers via meat and dairy prices (O'Donoghue et al. 2019).

The fundamental elements expected to change economic surplus can be illustrated using supply and demand curves. The supply curve $\left(\mathrm{S}_{\mathrm{T}}\right)$ and demand curve (D) represent the soybean market before the management intervention (Fig. 1A). The consumer surplus represents the area above the equilibrium price $\left(\mathrm{P}_{\mathrm{o}}\right)$ and below the demand curve (area 1) and the producer surplus is the area below the equilibrium price $\left(\mathrm{P}_{\mathrm{o}}\right)$ but above the supply curve (area 2 ). The total economic surplus is the union of areas 1 and 2 .

This analysis compares the current U.S. soybean market, in which fluopyram is gradually being adopted to avert SDS losses, to a counterfactual where fluopyram does not become available. If the fluopyram tactic was adopted in SDS-affected areas, this would increase supply, shifting the supply curve to the right from $S_{\mathrm{T}}$ to $\mathrm{S}_{1 \mathrm{FT}}$, causing the equilibrium price to fall $\left(\mathrm{P}_{1}\right)$, which would occur if the value of reduced SDS-associated yield losses were greater than the increased costs of SDS control (Fig. 1B). The consumer surplus would grow from the decline in equilibrium price from $P_{o}$ to $P_{1}$, because consumers would be paying a lower price at $P_{1}$ (adding regions 3,4 , and 5), and more consumers could enter the market at the lower price. The producer surplus would experience a mixed effect. It would grow from the decrease in marginal costs (region 6) and increased soybean production (region 7) but also shrink from the fall in price (loss of region 3). The amount of net change in total surplus depends on the proportionate increase in soybean production, variable input costs, and the elasticities of supply and demand, which reveal how producers and consumers respond to changes in price.

We estimated the benefits of the fluopyram tactic through a threestep strategy. First, as a baseline, we evaluated U.S. soybean production affected by SDS without the adoption of fluopyram-treated seed.
To discover potential damage to soybean yield by $F$. virguliforme, we predicted soybean production under SDS pressure without fluopyram seed treatment. We next modeled the adoption of fluopyram seed treatments applied to soybean production at risk of SDS. We assumed that growers would adopt fluopyram-treated seed as they learned about this prophylactic management strategy and began to plant treated seed in areas at risk for economic loss to SDS. Although the use of fluopyram-treated seed will incur additional production costs, the resulting reduction of SDS-associated yield loss would shift the supply curve to the right. To estimate the value of potential gains to growers adopting fluopyram-treated seed, we compared the quantities and prices of soybean produced with and without adoption of fluopyram-treated seed annually throughout the time horizon of the fluopyram adoption path.

Management-induced yield change parameterization. The economic impact was determined by comparing costs and benefits from the fluopyram seed treatment. Current U.S. soybean production acted as a baseline estimate of a soybean market that has incorporated losses due to SDS, allowing a comparison to evaluate the impacts of SDS on soybean yield by the application of fluopyram seed treatments (USDA-NASS 2017). To develop the counterfactual, we applied the percent yield change reported by the Kandel et al. (2018a) meta-analysis of over 200 field trails in 12 states during 2013 to 2015 , between the soybean seed treated with a commercial base plus fluopyram and soybean treated with a commercial base alone. To isolate benefits from fluopyram, the commercial base treatment included a nematistat and insecticide (Bacillus firmus with clothianidin) and three fungicides (metalaxyl, penflufen, and prothioconazole) known not to target $F$. virguliforme. Although $B$. firmus is intended to account for nematistatic activities of current commercial base seed treatments, in comparison with nematistatic activity against nematodes by fluopyram, growers may receive yield benefits beyond the conventional base, which were included in this analysis. These additional benefits from fluopyram could occur by preventing a potential synergistic activity of Heterodera glycines and $F$. virguliforme causing elevated SDS severity (Xing and Westphal 2006). Additionally, all field site locations had a historical presence of SDS with a diversity of disease severity that enabled characterization of yield benefits under a range of disease pressure (Kandel et al. 2018a). Also, field site locations included multiple soybean cultivars with varying levels of SDS resistance. The yield difference between the fluopyram-enhanced seed treatments and the counterfactual of soybean production with only a commercial base seed treatment was a $7.6 \%$ yield increase under $F$. virguliforme pressure (Kandel et al. 2018a). This yield gain only applies to fields
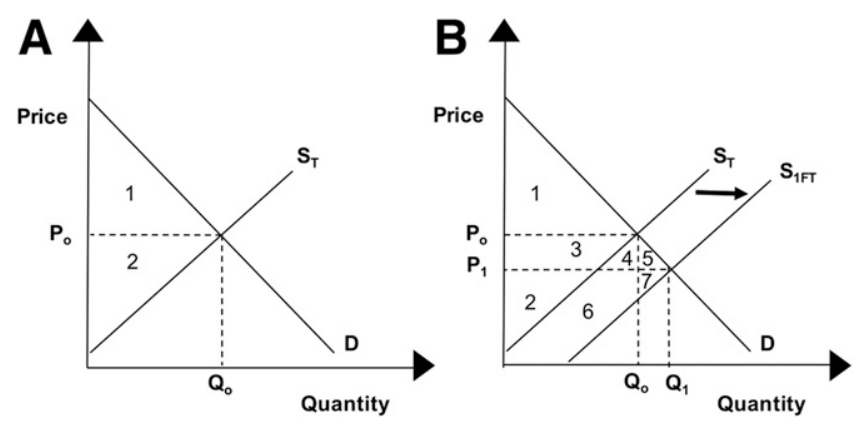

Fig. 1. Proposed soybean supply shifts under fluopyram seed treatment. A, Current U.S. soybean production market. $\mathrm{S}_{\mathrm{T}}=$ soybean supply curve with current adoption seed treatment for sudden death syndrome (SDS), $\mathrm{D}=$ demand curve, $\mathrm{P}_{\mathrm{o}}=$ original equilibrium price, $Q_{0}=$ original equilibrium quantity, 1 = region of consumer surplus, and 2 = region of producer surplus. B, Proposed shift in U.S. soybean production market if fluopyram seed treatment was adopted. $\mathrm{S}_{\mathrm{T}}=$ soybean supply curve with current adoption seed treatment for SDS; $\mathrm{S}_{1 \mathrm{FT}}=$ soybean supply curve under projected fluopyram seed treatment adoption for SDS; $D=$ demand curve; $P_{0}=$ original equilibrium price; $Q_{0}=$ original equilibrium quantity; $P_{1}=$ new equilibrium price; $Q_{1}=$ new equilibrium quantity; $1,3,4$, and $5=$ region of consumer surplus; and 2, 6, and $7=$ region of producer surplus. 
affected by SDS, and assumes no future advancement of soybean genetic resistance to SDS during the 15-year time horizon of this study.

Determining changes in economic surplus. The precise spatial extent of SDS in the U.S. remains unclear. Specific environmental predictors of this disease remain ambiguous to growers and researchers because SDS incidence is very heterogeneous, even within an infested field (Allen et al. 2017; Roy et al. 1997). SDS is spreading and has been reported in new soybean production states over the last two decades but the incidence of this disease is not reported. Often, the impact of SDS is estimated by bushels lost based on disease surveys; feedback from university, industry, extension, and farmer personnel; and personal exposure to disease severity or incidence. From these reports, percent disease loss is estimated and formulated to total bushels lost for each soybean disease based upon predicted yield before estimated losses (Crop Protection Network 2016). Total incidence or area of soybean production with SDS present and at economic risk to yield loss across the soybean production region can be calculated from annual reports of percent yield loss (Allen et al. 2017; Crop Protection Network 2016; United Soybean Board 2017) divided by an average disease severity (e.g., the intensity of disease when presence) across affected soybean acres of $10.0 \%$ (Roy et al. 1997). This calculated incidence of SDS across U.S. soybean production was determined to be at economic risk of SDS-associated yield loss and assumed for gradual adoption of fluopyram-treated soybean seed to alleviate SDS-associated yield losses within this analysis.

To place an economic value on potential reduction in SDS-related yield loss from the use of fluopyram as a seed treatment, we assumed an adoption path similar to that observed for neonicotinoid soybean seed treatments, which were introduced to prophylactically manage insect pests of soybean, starting in 2004. Neonicotinoid seed treatments were rapidly adopted by $6 \%$ of U.S. growers in 2006, leading to a conservative estimate of $34 \%$ of soybean production planting neonicotinoid-treated seed in 2011 (Douglas and Tooker 2015). Applying the key values of percent soybean area planted with neonicotinoid seed treatments in 2006 and 2011, with an upper limit of $90 \%$, revealed that neonicotinoid seed treatments were primarily adopted over a 15-year time frame (Fig. 2; Supplementary File $\mathrm{S} 1)$. We applied the adoption path estimated for neonicotinoid treatments on soybean seed to model the adoption of fluopyram seed treatments as a logistic trend, with a maximum adoption of $90 \%$ (rather than $100 \%$, because some growers are averse to adopting new technologies) (Fernandez-Cornejo et al. 1994).

Early evidence of the adoption of fluopyram-amended seed treatment appears strikingly similar to that of neonicotinoid seed treatments. Fluopyram-treated soybean seed were commercially available to U.S. soybean producers from 2014 to 2018 . Fluopyram-treated soybean seed was planted across 3 million acres in 2016, and increased to 8.5 million acres in 2018 (J. Mullock, BASF; personal communication). To model the future adoption of fluopyram, we applied the same adoption curve assumptions used by Fernandez-Cornejo et al. (1994) for the neonicotinoid seed treatments and that only growers with fields at risk of SDS infestation might adopt it. Therefore, the ceiling for future adoption of fluopyram was selected at $90 \%$. Fitting the observed percentages of soybean area planted with fluopyram seed treatments in 2016 and 2018, with a logistical adoption function and an upper adoption limit of $90 \%$, implied that fluopyram seed treatments would be primarily adopted over a 15 -year time frame as well (Fig. 2; Supplementary File S1).

The technologies presented in Figure 2 have similar capital inputs and benefits to growers, and the adoption area is very similar to that of a pest-specific seed treatment. The barriers for growers to adopt fluopyram-treated seed are lower than for other technologies because many growers already own the equipment needed to plant the seed and only require capital for purchasing treated seed, along with an awareness of seed treatments as a cost-effective management tactic. Therefore, when considering barriers to adoption, we also propose to evaluate economic impacts from a fluopyram-treated seed adoption timeline explored over 15 years.

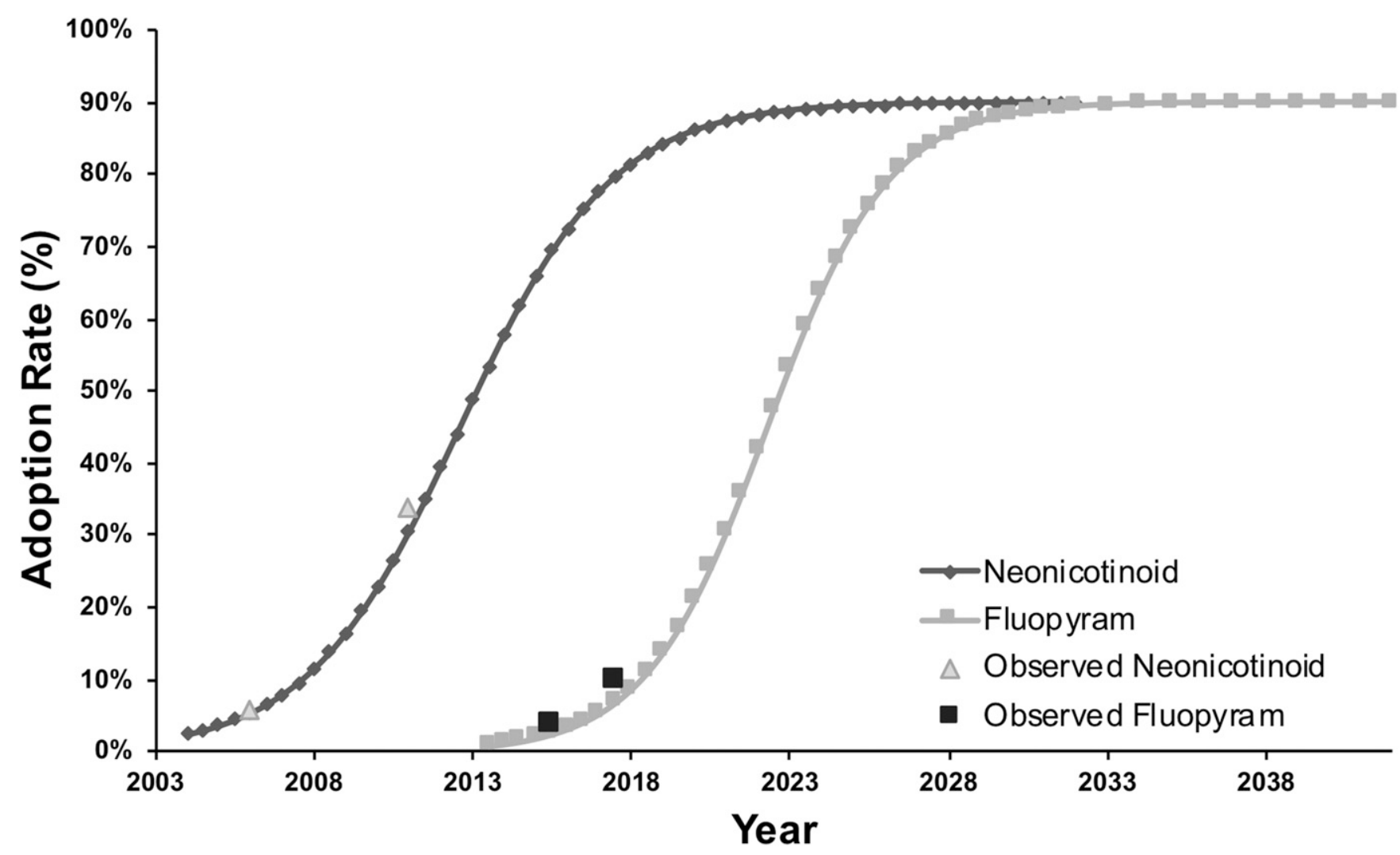

Fig. 2. Adoption path of soybean seed treatments. The dark line indicates percent adoption area of soybean neonicotinoid seed treatments from 2004 to 2025 and all soybean treatments for pest prevention from 1996 to 2017 in the U.S. soybean production, and the lighter line indicates predicted fluopyram adoption from 2018 to 2032 for SDS-associated yield loss aversion. 
Data to evaluate economic surplus and net present value. To assess surplus changes in a parallel supply shift of $S_{T}$ to $S_{1 F T}$, we determined the proportional vertical supply shift from $\mathrm{P}_{\mathrm{o}}$ to $\mathrm{P}_{1}$, denoted as $K$, and $Z$, the percent change in the equilibrium soybean price between soybean production with no adoption of fluopyram and the gradual adoption of fluopyram within SDS-affected areas annually (Fig. 1) (Alston et al. 1998a; Song and Swinton 2009). We assumed a parallel supply shift of linear supply curves (Fig. 1) and a linear demand curve to calculate the change in consumer and producer surplus with and without fluopyram adoption as below:

$$
\begin{aligned}
& \Delta P S_{U S}=P_{o} Q_{U S}(K-Z)\left(1+0.5 Z \mathrm{y}_{U S}\right) \\
& \Delta C S_{U S}=P_{o} C_{U S} Z\left(1+0.5 Z \eta_{U S}\right) \\
& \Delta T S_{U S}=\Delta P S_{U S}=\Delta C S_{U S}
\end{aligned}
$$

where $\triangle P S_{U S}$ is the change of producer surplus, $\Delta C S_{U S}$ is the change in consumer surplus, and $\Delta T S_{U S}$ is the change to total surplus, all within the United States. Underlying the calculation of consumer or producer surplus are $P_{o}=$ initial soybean market price, $Q_{U S}=$ U.S. soybean production, and $C_{U S}=$ U.S. soybean consumption. The slopes of the supply and demand curves can be represented by $\mathrm{y}_{U S}$ = supply elasticity and $\eta_{U S}=$ the demand elasticity, respectively (Alston et al. 1998a; Song and Swinton 2009). Values for these elasticities were gathered from literature.

To calculate changes to economic surplus, we first estimated soybean quantity changes between the scenarios of with or without fluopyram adoption, which were determined through the yield loss reduction equation below:

$$
\begin{aligned}
\text { Yield }= & (1-s-e) \times Y^{\prime}+s \times[1-d(1-f \times \text { Adopt } \%)] \times Y^{\prime}+ \\
& e \times[1-d(1-f \times 0)] \times Y^{\prime}
\end{aligned}
$$

where Yield is the quantity soybean yield produced under each scenario, $s$ is the low incidence of soybean area with economic damage from SDS, and $e$ is the epidemic jump in proportion during 5-yearly epidemics. $Y^{\prime}$ represents the soybean yield that is SDS free, assumed to be the United States Department of Agriculture (USDA) projected soybean quantities. The damage proportion from SDS of $7.6 \%$ is represented by $d$. Parameter $f$ represents the proportional damage reduction from fluopyram, assumed to be $100 \%$. Adopt $\%$ is the proportion of growers adopting fluopyram in areas normally experiencing SDS economic damage. We assume $0 \%$ fluopyram adoption in epidemic areas that do not normally experience SDS damage; thus, damage from SDS epidemics in these areas is unmitigated.

Changes to soybean quantities produced were analyzed by categorizing soybean yield into the disease-free proportion $\left[(1-s-e) \times Y^{\prime}\right]$ and the proportion of soybean yield at risk to SDS-associated losses: $s \times[1-d(1-f \times A d o p t \%)] \times Y^{\prime}+e \times[1-d(1-f \times 0)] \times Y^{\prime}$. If growers adopted fluopyram-treated seed, then SDS-associated yield losses would decrease by $7.6 \%$ per acre within the proportion of soybean yield at risk to SDS-associated losses. The proportionate difference of soybean quantities produced by adoption of fluopyram-treated seed when compared with nonadoption of fluopyram in areas affected by SDS represents total yield loss averted. To quantify the vertical supply shift, we considered four parameters that underpin changes in economic surplus: soybean and demand supply elasticities, costs of fluopyram adoption, incidence of SDS, and the projected rate at which farmers adopt fluopyram. The value of changes to surplus between the scenarios of fluopyram adoption and nonadoption was summed from 2018 to 2032 and discounted at an annual rate of 5\% to determine the net present value (NPV) (Alston et al. 1998a).

Supply and demand elasticities. Elasticities were reviewed from the literature and presented in Table 1. Because similar values for supply elasticities were recorded from several different literature sources, we chose 0.30 to represent the supply elasticity and used -0.61 as the demand elasticity.

Cost change. The changes in variable input costs were calculated from variable cost differences in annual production budgets between the two management options of the commercial base seed treatment or using commercial base with a fluopyram-amended seed treatment. The commercial base seed treatment costs $\$ 12$ per seed unit $(140,000$ seeds per seed unit) versus $\$ 25$ per seed unit for the commercial base seed treatment with fluopyram (Gaspar et al. 2017). The increased cost of \$13/acre for fluopyram-amended seed treatments was assumed to entail an additional $\$ 0.32$ per acre in borrowing costs at a $5 \%$ interest rate, resulting in a total increased cost for fluopyram seed treatment of $\$ 13.32$ per acre, a $2.8 \%$ increase in total production costs (Ward et al. 2018) (Supplementary Table S1).

Incidence of SDS in U.S. soybean production. The incidence of SDS in U.S. soybean production was estimated from annual yield losses from 1996 to 2015 (Allen et al. 2017) and 2011 (United Soybean Board 2017), and soybean production data (USDA-ERS 2019) from 1996 to 2015 (Supplementary File S1). Annual percent yield loss $\left(Y_{\text {Loss }}\right)$ was estimated as follows and used as incidence of SDS in U.S. soybean production:

$$
Y_{\text {Loss }} \text { share }=Y_{\text {Loss }} /\left(Y_{\text {Harvest }}+Y_{\text {Loss }}\right)
$$

where $Y_{\text {Loss }}$ share is the estimated proportional loss in soybean production due to SDS, which is divided by total potential yield, measured as the total bushels harvested in the U.S. ( $\left.Y_{\text {Harvest }}\right)$ plus the additional soybean bushels lost to $\operatorname{SDS}\left(Y_{\text {loss }}\right)$. Proportional yield loss was utilized to estimate incidence from the following equation:

$$
Y_{\text {Loss }} /\left(Y_{\text {Harvest }}+Y_{\text {Loss }}\right)=\operatorname{Prob}(S D S) \times Y_{\text {Loss }} \mid S D S
$$

The percent yield loss occurring from SDS is a function of the incidence of SDS [Prob(SDS)] and the average percent yield loss occurring when severe SDS is present $\left(Y_{\text {Loss }} \mid S D S\right)$. We used this equation to estimate incidence by dividing proportional yield loss by average disease severity of $10 \%$ across affected soybean acres (Roy et al. 1997). Holding disease severity constant assumes that incidence will reflect the variability of years with greater SDS yield loss. The incidence of SDS with an economic impact across the soybean production region was estimated from yield loss data collected annually from 1996 to 2015 (Fig. 3). Over the last two decades of U.S. soybean reports, SDS incidence appeared to group at two distinct levels (Fig. 3A). The first level we deemed SDS low incidence, or incidence without epidemics (below $11.9 \%$ ), ranging from $1.5 \%$ in 1996 to $11.0 \%$ in 2015 , increasing at a linear trend of $0.168 \%$ annually (Fig. 3A). Although we can estimate an annual rate of increase to a very precise rate, the accuracy of this annual increase of incidence may be much lower than calculated. Interestingly, a second group of SDS incidence was observed at levels of incidence above $11.9 \%$

\begin{tabular}{|c|c|c|c|c|c|c|}
\hline Elasticity & $\begin{array}{c}\text { Masuda and Goldsmith } \\
2009\end{array}$ & $\begin{array}{l}\text { Zilberman et al. } \\
2010\end{array}$ & $\begin{array}{c}\text { Reimer et al. } \\
2012\end{array}$ & $\begin{array}{c}\text { Lybbert et al. } \\
2014\end{array}$ & $\begin{array}{l}\text { Haile et al. } \\
\quad 2016\end{array}$ & $\begin{array}{c}\text { Kim and Moschini } \\
2018\end{array}$ \\
\hline U.S. supply & $\ldots$ & 0.22 & $\ldots$ & 0.30 & 0.30 & 0.38 \\
\hline U.S. demand & -0.61 & $\ldots$ & $\ldots$ & $\ldots$ & $\ldots$ & $\ldots$ \\
\hline U.S. export demand & $\ldots$ & $\ldots$ & -0.90 & $\ldots$ & $\ldots$ & $\ldots$ \\
\hline $\begin{array}{l}\text { Rest of world } \\
\text { supply }\end{array}$ & $\ldots$ & $\ldots$ & $\ldots$ & $\ldots$ & $0.34-055$ & $\ldots$ \\
\hline
\end{tabular}
(Fig. 3A), which corresponded to years with epidemic levels of SDS-associated yield loss (Leandro et al. 2013). SDS epidemics have been observed to cause spikes in yield loss approximately every 4 to 5 years; the epidemics seem to correspond to decreases in annual mean temperature in the prior year (Fig. 3B). The low incidence of

Table 1. Supply and demand elasticities for soybean for the United States and rest of the world 
SDS was modeled over the 15-year analysis using the low incidence values, starting at $9.8 \%$ in 2018 and increasing annually at $0.168 \%$ to a final incidence of $12.2 \%$ in 2032 . Every 5 years, the average incidence of the four previous epidemics was applied at $19.0 \%$, with the first epidemic occurring in 2019, because 5 years had passed since the last epidemic.

Adoption of fluopyram-amended seed. The adoption path of fluopyram across SDS-affected soybean production was based upon the estimated logistical adoption path of fluopyram-treated seed (Fig. 2). We applied the logistical adoption pattern of fluopyram seed treatments from 2014 to 2032 to model the adoption path of fluopyram seed treatments. Fluopyram has been commercially available on the market since 2014; thus, the adoption rate starts in 2018 at $8.0 \%$. Following a logistical trend, the adoption rate swiftly increases to $12.5 \%$ in 2019 and $19.2 \%$ in 2020 (Fig. 2). This increasing adoption rate of fluopyram corresponds, in part, to public outreach activities after the research was completed in 2018.

Price of soybean. Projections of prices were taken from USDA through 2029 values (O'Donoghue et al. 2019). Projections were held constant at 2029 prices through 2032, mimicking trends from 2026 to 2029.

Quantity of soybean. The quantity of soybean produced was taken from historical accounts of soybean produced in the United States (USDA-ERS 2019) as well as projections to 2028 from the USDA
(O’Donoghue et al. 2019) and held stable at 2029 quantities through 2032.

Costs from research and outreach. Previous costs of validation research associated with fluopyram and conducted by public universities were gathered from National Soybean Checkoff Base, which occurred from 2014 to 2019, totaling $\$ 844,000$ across seven U.S. states (United Soybean Board 2019) (Supplementary File S1). Future research costs were estimated from National Soybean Checkoff Base funds allocated to SDS and fluopyram research and communication in 2019 at $\$ 93,500$, and which was presumed to be allocated again in 2020 (Table 2). Additionally, we assumed that there was one principal investigator and one technician for each field trial in Delaware, Indiana, Iowa, Kentucky, Michigan, South Dakota, and Wisconsin who would dedicate $5 \%$ of their annual time to conducting individual trials (Table 2). These associated research costs were estimated at $\$ 17,600$ per trial site after incorporating $30 \%$ fringe benefits and $50 \%$ indirect costs (Table 2).

Outreach costs were estimated from 20 extension educators in each state allocating $2 \%$ of time annually from 2018 to 2032, repeated in each of the 33 soybean-producing states in a method similar to that of Song and Swinton (2009), at a total of $\$ 1,783,000$ annually. An average salary was estimated from the 2019 reported values of Michigan extension educators' salaries on a continuing track, after

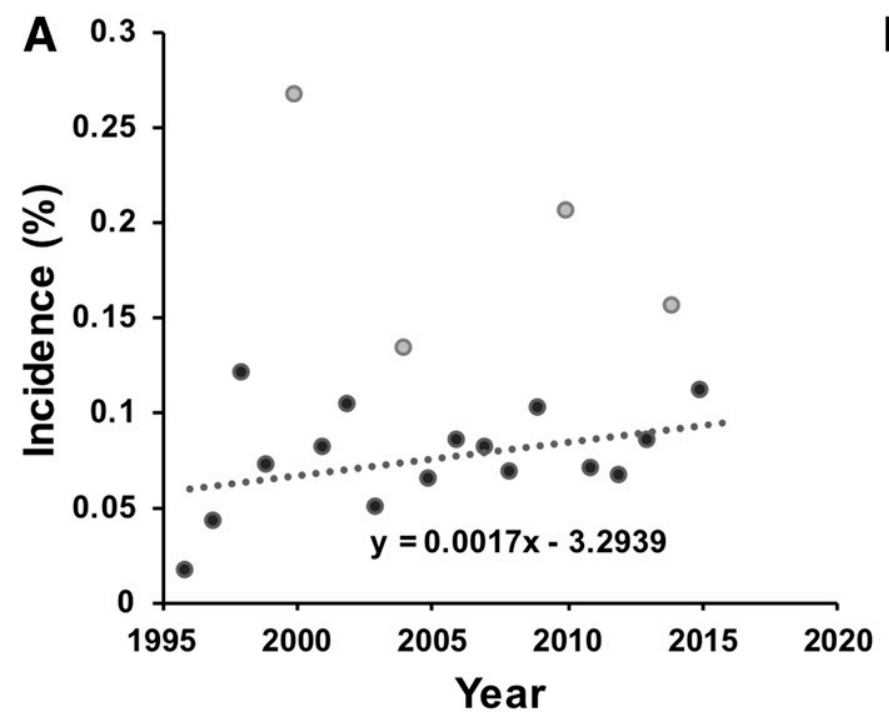

- Low incidence ...... Linear (Low incidence)

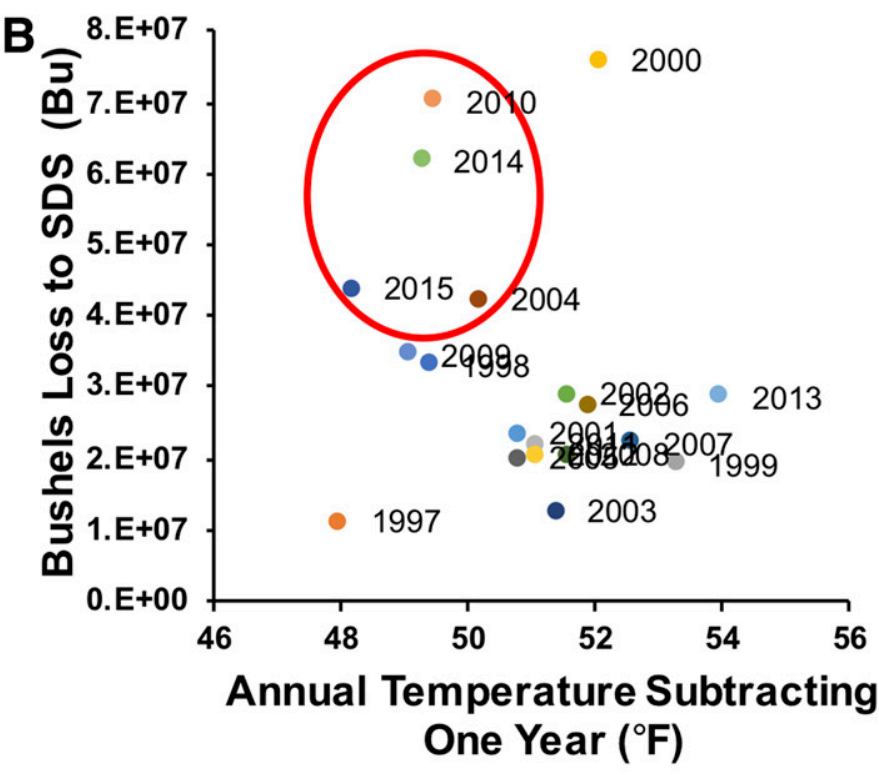

Fig. 3. Soybean sudden death syndrome (SDS) incidence. Scatter plot of incidence of SDS syndrome from 1996 to 2015 across U.S. soybean production region. A, Low incidence with trend line and high or epidemic incidence. B, Scatter plot of relationship of yield loss to soybean sudden death syndrome to mean annual temperature 1 year before yield loss occurred. The circle denotes epidemic years when low temperatures preceded the year of an epidemic loss.

Table 2. Costs associated with fluopyram seed treatments and communication of research ${ }^{\mathrm{a}}$

\begin{tabular}{ccccc}
\hline & \multicolumn{4}{c}{ Cost per trial across states $(\mathbf{U S} \mathbf{\$})^{\mathbf{b}}$} \\
\cline { 2 - 4 } Year & Iowa & Michigan & Multilocation and regional trials & Associated research costs \\
\hline 2014 & $\ldots$ & $\ldots$ & 121,196 & 125,844 \\
2015 & 129,159 & $\ldots$ & 164,811 & 59,711 \\
2016 & 121,196 & 21,500 & 50,000 & 82,248 \\
2017 & $\ldots$ & $\ldots$ & 72,369 & 93,998 \\
2018 & $\ldots$ & $\ldots$ & 65,328 & 82,248 \\
2019 & $\ldots$ & 15,200 & 78,354 & 82,248 \\
2020 & $\ldots$ & 15,200 & 78,354 & 82,248 \\
\hline
\end{tabular}

${ }^{\text {a }}$ Costs were gathered from locations in Delaware, Indiana, Iowa, Kentucky, Michigan, South Dakota, and Wisconsin along with associated research costs from 2014 to 2020.

${ }^{\mathrm{b}}$ Costs for publicly conducted fluopyram seed treatment research and outreach were gathered from the United Soybean Board (2019). 
incorporating 30\% fringe benefits and 50\% indirect costs, and applied as salary for all extension agents.

\section{Results}

The NPV of adopting fluopyram for SDS control was estimated based upon comparison of two scenarios across soybean acreage at risk of SDS with and without fluopyram adoption. Without the prophylactic control from this fungicidal seed treatment, soybean production would have suffered an estimated loss of 645 million bushels from 2018 to 2032 stemming from SDS, representing $0.96 \%$ of projected U.S. soybean production. Adopting fluopyramtreated seed reduces SDS-related losses to U.S. soybean production by an estimated $46.4 \%$, decreasing production losses from 645 million bushels to 299 million bushels across 2018 to 2032. The increase of the estimated 346 million bushels of soybean represents the benefit of adopting fluopyram-treated seed on SDS at-risk acreage by averting associated yield loss. NPV analysis of this increase over 15 years comes to $\$ 5,829$ million in net benefits.

We applied an economic surplus approach to determine the value of fluopyram adoption, because not only do costs of production rise but also the change in soybean output may alter market prices. Specifically, the increased soybean production entering the market from fluopyram adoption in SDS at-risk areas will cause a predicted drop in soybean prices. Although the price reduction will slightly shrink producer surplus, the increase in soybean quantity produced due to fluopyram adoption will expand consumer surplus. The mechanism for this is that the decrease in soybean prices allows more buyers to enter the market and purchase soybean crops at the lower price (typically for livestock feed). Therefore, a shift of the supply curve to the right will expand consumer surplus from adoption of fluopyram in at-risk SDS areas, increasing the estimated benefits.

Sensitivity analysis. Key parameters that may affect the economic impact of fluopyram-treated seed on soybean acreage at risk of SDS includes supply elasticity, disease incidence, price change, and adoption rate. To understand the impacts of multiple variables, the sensitivity of this analysis was explored through combining all variables in either a worst-case or best-case scenario (Table 3). Because similar values for supply elasticities were recorded from several different literature sources and were similar to the value we used for this analysis, we did not model changes to values of supply elasticities. Because the activity of fluopyram is not as broad as the neonicotinoid seed treatments upon which we based several assumptions in developing the adoption path, we reduced the maximum ceiling for adoption of fluopyram to represent a reduction in potential growers adopting this chemistry. Also, additional fungicidal seed treatment chemistries targeting SDS will be on the market starting in 2019
(Syngenta 2019); therefore, we adjusted the adoption rate of fluopyram based upon observed adoption of a neonicotinoid seed treatment that became available to growers 5 years after initial neonicotinoid soybean seed treatments came on the market. For the other two key variables of SDS incidence and soybean prices, we adjusted outcomes by one trend-adjusted standard deviation up or down as appropriate for "worst-case" and "best-case" scenarios.

The level of incidence of soybean acres at economic risk to SDS in the United States is a primary factor in the economic benefits of fluopyram-treated seed for alleviating yield losses attributable to SDS. Currently, no aggregate level of SDS incidence has been estimated across U.S. soybean production. Therefore, we estimated this parameter based on percent annual yield loss estimates of total soybean production attributed to SDS, and an average severity of $10 \%$. This method overlooks many local-scale environmental factors, in addition to assuming a strong linear relationship between severity and incidence to generate yield loss. Also, SDS is being discovered in new regions of the United States each growing season; thus, the rate at which incidence increases may be lower herein than actually realized. To account for uncertainties of the incidence of soybean acres at risk to SDS, we calculated the trend-adjusted standard deviation at low SDS incidence (i.e., incidence below 11.9\%) during 1996 to 2015 to be $5.8 \%$. This standard deviation represented $77.1 \%$ change of incidence from the mean low incidence of $7.6 \%$ from 1996 to 2015. To represent the recorded variation of SDS low incidence, we then reduced SDS low incidence of $77.1 \%$ in 2018 to $2.2 \%$ for the worst-case scenario. In the best-case scenario, we increased SDS incidence by one standard deviation, from 77.1 to $17.4 \%$. Although low incidence was altered in the sensitivity analysis, both scenarios still had epidemics in 2019, 2024, and 2029 with an incidence of $19 \%$, and SDS low incidence still increased at a rate of $0.168 \%$ annually.

Soybean prices are a key factor in valuation of benefits in this analysis. Prices of soybean over 30 years from 1989 to 2018 have varied from a high of $\$ 15.54$ per bushel in 2012 to a low of $\$ 6.29$ per bushel in 2002 after converting all prices to 2018 U.S. dollars (O'Donoghue et al. 2019). We wanted to account for price fluctuations in the soybean market, in order to explore impacts upon benefits generated from fluopyram seed treatment in SDS at-risk areas. In order to remove inflationary price distortions, we adjusted soybean prices from 1989 to 2018 for inflation by converting to 2018 U.S. dollars. The standard deviation of inflation-adjusted soybean prices from 1989 to 2018 was $\$ 2.43$, for a coefficient of variation of $23.2 \%$ around the mean soybean price of $\$ 10.45$. To account for this observed variation in soybean prices in the sensitivity analysis, we decreased soybean prices by $23.2 \%$ annually in the worst-case scenario

Table 3. Sensitivity analysis of economic impacts to U.S. soybean production for fluopyram sudden death syndrome management from 2018 to 2032 (in millions U.S.\$)

\begin{tabular}{|c|c|c|c|}
\hline \multirow[b]{2}{*}{ Parameter changed } & \multicolumn{3}{|c|}{ Fluopyram } \\
\hline & Worst case & Baseline & Best case \\
\hline \multicolumn{4}{|l|}{ Incidence $^{\mathrm{a}}$} \\
\hline Starting rate in 2018 & $2.2 \%$ & $9.8 \%$ & $17.4 \%$ \\
\hline \multicolumn{4}{|l|}{ Adoption rate $\mathrm{b}^{\mathrm{b}}$} \\
\hline 2018 Percentage & $8.0 \%$ & $8.0 \%$ & $8.0 \%$ \\
\hline 2022 Percentage & $20.4 \%$ & $38.9 \%$ & $40.2 \%$ \\
\hline \multicolumn{4}{|l|}{ Adoption ceiling ${ }^{\mathrm{c}}$} \\
\hline Maximum adoption in 2032 & $50 \%$ & $\ldots$ & $90 \%$ \\
\hline \multicolumn{4}{|l|}{ Soybean price ${ }^{\mathrm{d}}$} \\
\hline Price per bushel average (2019-2032) & $\$ 7.34$ & $\$ 9.33$ & $\$ 11.40$ \\
\hline Price change $(\%)$ & $-23.2 \%$ & $\ldots$ & $+23.2 \%$ \\
\hline Gross benefits & \$692 million & $\$ 9,531$ million & $\$ 18,548$ million \\
\hline Net benefits & $\$ 407$ million & $\$ 5,829$ million & $\$ 11,303$ million \\
\hline Percent change to reference (\%) & $-93.0 \%$ & $\ldots$ & $93.9 \%$ \\
\hline
\end{tabular}

\footnotetext{
${ }^{a}$ Low incidence was altered by $5.8 \%$ or one trend-adjusted standard deviation of the mean in 2018 in the best- and worst-case scenarios.

$\mathrm{b}$ Adoption rate was changed by $1.2 \%$ in 2022 in the best- and worst-case scenario, according to respective adoption ceilings.

c Adoption ceiling was reduced to $50 \%$ in the worst-case scenario, and remained unchanged in the best-case scenario at $90 \%$.

d Soybean prices were altered by $23.2 \%$ or one trend-adjusted standard deviation of the mean in the best- or worst-case scenario.
} 
and added $23.2 \%$ to soybean prices annually in the best-case scenario.

As an ex ante analysis, we projected future adoption of fluopyram based on adoption rates from 2016 and 2018. However, additional seed treatments registered for SDS management are coming on the market in 2019 (Kandel et al. 2019a; Syngenta 2019). To take these additional products entering the SDS seed treatment market into consideration, we reviewed the adoption path of different neonicotinoid soybean seed treatments, because neonicotinoids had an adoption path similar to that of fluopyram. Imidacloprid (Bayer Crop Science) and thiamethoxam (Syngenta) are both neonicotinoid seed treatments that were registered in 2004 for use on soybean and quickly adopted (Douglas and Tooker 2015; Schulz et al. 2007). Clothianidin (Bayer Crop Science) was registered 5 years later. By 2012, after just 3 years, this product was estimated to be planted on 1 million soybean acres, or $1.2 \%$ of the U.S. soybean area (Myers and Hill 2014). In parallel, 5 years postregistration of fluopyram for SDS management, new chemistries are currently proposed to be registered as seed treatments for SDS of soybean (Syngenta 2019). With similar timelines for registration of products, as well as similar adoption paths of the seed treatments, we applied the observed values of clothianidin to model future adoption of new SDS seed treatments that could affect fluopyram adoption. Therefore, we reduced the adoption of fluopyram by $1.2 \%$ in 2022 in the worst-case scenario, and increased it by $1.2 \%$ in 2022 in the best-case scenario.

Apart from the rate of adoption of fluopyram, we also conducted sensitivity analysis for a ceiling adoption level of fluopyram. We modeled the adoption path of fluopyram on that of neonicotinoid seed treatments. However, neonicotinoids have a much broader registered activity against soybean pests than fluopyram, including the Hemiptera, Coleoptera, Diptera, and Lepidoptera insect orders (Myers and Hill 2014). Fluopyram is registered specifically for $F$. virguliforme, Septoria glycines, and several soilborne nematodes (H. glycines, Rotylenchulus reniformis, Meloidogyne incognita, Hoplolaimus spp., and Pratylenchus spp.) (Bayer Crop Science 2016). This broad-spectrum activity of neonicotinoid seed treatments may have promoted widespread adoption of this chemistry by growers for pest management. The reduced broad-spectrum activity of fluopyram seed treatments when compared with neonicotinoids may decrease the number of total growers who would be willing to adopt this seed treatment. To represent this potential reduction in soybean growers adopting fluopyram, we reduced the ceiling of adoption to $50 \%$ in the worst-case scenario. In the best-case scenario, the adoption ceiling remained unchanged at $90 \%$.

The sensitivity analysis indicated a $93.0 \%$ decrease in worst-case and $93.9 \%$ increase in best-case scenario of net benefits, relative to the baseline analysis of $\$ 5,829$ million in net benefits (Table 3). Changing variables critical to this analysis revealed that this analysis is highly sensitive to soybean prices, adoption path, and ceiling, as well as the incidence of SDS at-risk soybean acres.

\section{Discussion}

Soybean SDS is a leading cause of soybean yield losses, and was ranked among the top five yield-reducing diseases in U.S. soybean during 2010 to 2014 (Allen et al. 2017). Industry reports SDS incidence on up to $80 \%$ of U.S. soybean acreage (Bayer Crop Science 2017). However, only part of this area reflects "economic incidence" where soybean yield loss occurred. Based on severity reports and 20 years of yield loss data, we found an economic incidence near $10 \%$ where SDS is causing yield loss. At this economic incidence rate, we find moderate economic benefits of fluopyram-amended seed treatments of $\$ 5,829$ million for alleviation of SDS-associated yield losses. Overall, this NPV represents an estimated $1.4 \%$ of the projected discounted national gross value of soybean production over the 15-year estimation. Although the estimated benefit of fluopyram is a small percentage of the gross value of this crop, this value reflects the proportion of the national soybean production with SDS incidence that would receive an economic benefit from fluopyram adoption. Because our parameter assumptions here are conservative and yield losses from soilborne diseases are often underreported (Crop
Protection Network 2016), the actual economic benefits may be greater than projected here. The moderate economic benefits estimated from this framework suggest that public investments in validation research and outreach of privately developed technology are beneficial to society.

Previous studies have compared adoption of management practices to alleviate yield loss from pests or diseases at an aggregate level and provide a framework to explore our findings. Concern about Asian soybean rust (Phakopsora pachyrhizi) sparked the investigation of economic impacts through fungicide management applications. Johansson et al. (2006) estimated that, within the 2010 growing season, a total of $\$ 623$ million of soybean production would be lost if no treatment was applied. Additionally, exploration of economic losses stemming from soybean aphid (Aphis glycines), with and without IPM scouting management or fungicide management within 2010 as well, ranged from $\$ 274$ to 698 million across affected soybean production (Song and Swinton 2009). We found that, if fluopyram were not adopted, annual losses to SDS ranged from \$297 to 407 million in nonepidemic years to $\$ 583$ to 636 million during epidemic years. The nonepidemic annual loss estimates from SDS fall within the range of soybean aphid and below Asian soybean rust. The higher impact of epidemics, greater than Asian soybean rust, originates from the nearly doubling of acres at risk to economic loss from SDS when these outbreaks occur. Previously estimated annual soybean yield losses stemming from SDS have been valued at annual soybean prices to determine economic losses. During nonepidemic years, economic valuation of estimated annual yield losses stemming from SDS have varied from \$29 million in 1996 to \$474 million in 2016, with each nonepidemic year from 2009 to 2016 causing an excess of $\$ 300$ million in losses (Bandara et al. 2020; Navi and Yang 2016). Epidemic years caused greater losses, ranging from $\$ 275$ to 445 million during the 2004 and 2000 growing seasons, respectively, to $\$ 673$ to 863 million during the 2014 and 2010 growing seasons, respectively (Bandara et al. 2020). Our estimates of annual losses to SDS fall within the range of estimations of economic losses stemming from SDS during more recent growing seasons, as incidence of SDS increased from 1996 to 2016 to a level similar to that within our framework.

The profitability of fluopyram-amended seed treatments and probability of a positive return on investment have previously been investigated at the farm level (Gaspar et al. 2017; Kandel et al. 2018a). These localized studies found that fluopyram was beneficial in sites with a history of SDS pressure but the probability of returns to growers decreased with increasing seed costs or decreasing soybean prices (Gaspar et al. 2017; Kandel et al. 2018a). Our sensitivity analysis reached similar findings. In the worst-case we model, if soybean prices fell by one standard deviation $(23.2 \%)$ while disease incidence decreased by one standard deviation $(77.1 \%$ in 2018$)$, the adoption rate of fluopyram dropped by $1.2 \%$ in 2022 , and the adoption ceiling was reduced to $50 \%$, then the net benefits would decrease by $93 \%$. By contrast, in the best case, if the rate of disease incidence rose by $77.1 \%$, soybean prices increased by $23.2 \%$, and the adoption rate rose by $1.2 \%$ in 2022 , then this seed treatment net benefits would rise by $94 \%$.

The adoption of fluopyram across the soybean acres at risk to SDS-associated yield losses could pose environmental costs that are difficult to value. Although fluopyram is active against $F$. virguliforme, the SDHI fungicide also has activity against other fungi (Santísima-Trinidad et al. 2018), which could cause environmental microbial communities to change in response to this seed treatment or aid in fungal communities losing sensitivity to this mode of action (Nettles et al. 2016). The costs associated with these environmental changes are difficult to parameterize and evaluate but should be evaluated when considering SDS management and the potential benefits derived from fungicidal seed treatments.

\section{Conclusions}

The economic impacts of public investment through research and outreach of a privately developed technology estimated from adoption of fluopyram to alleviate SDS-associated yield losses in at-risk 
acres revealed an overall benefit, with NPV of $\$ 5.8$ billion over 15 years, indicating that fluopyram can reduce the economic impact of SDS. This analysis also illustrates that the investment of validation research and outreach to discover and implement privately developed management tactics of diseases do have an overall economic benefit. Sensitivity analysis of this framework indicates that the market price of soybean, the incidence of SDS, and the adoption ceiling and path of this seed treatment can alter overall net benefits from fluopyram. Nonetheless, even in the worst-case scenario where all four of these factors were less favorable to fluopyram impacts, the NPV of fluopyram-amended seed treatment targeting SDS management still reached $\$ 407$ million. In sum, if growers adopt this fluopyram seed treatment to reduce economic yield losses caused by SDS as predicted, the overall economic benefits to soybean producers and consumers should be significant.

\section{Literature Cited}

Agrios, G. N. 2004. Plant Pathology. Elsevier Academic Press, San Diego, CA, U.S.A.

Allen, T. W., Bradley, C. A., Sisson, A. J., Byamukama, E., Chilvers, M. I., Coker, C. M., Collins, A. A., Damicone, J. P., Dorrance, A. E., Dufault, N. S., Esker, P. D., Faske, T. R., Giesler, L. J., Grybauskas, A. P., Hershman, D. E., Hollier, C. A., Isakeit, T., Jardine, D. J., Kelly, H. M., Kemerait, R. C., Kleczewski, N. M., Koenning, S. R., Kurle, J. E., Malvick, D. K., Markell, S. G., Mehl, H. L., Mueller, D. S., Mueller, J. D., Mulrooney, R. P., Nelson, B. D., Newman, M. A., Osborne, L., Overstreet, C., Padgett, G. B., Phipps, P. M., Price, P. P., Sikora, E. J., Smith, D. L., Spurlock, T. N., Tande, C. A., Tenuta, A. U., Wise, K. A., and Wrather, J. A. 2017. Soybean Yield Loss Estimates Due to Diseases in the United States and Ontario, Canada, from 2010 to 2014. Plant Health Prog. 18:19-27.

Alston, J. M., Beddow, J. M., and Pardey, P. G. 2009. Agricultural research, productivity, and food prices in the long run. Science 325:1209-1210.

Alston, J. M., Norton, G. W., and Pardey, P. G. 1998a. Science Under Scarcity: Principles and Practice for Agricultural Research Evaluation and Priority Setting. CAB International, New York, NY, U.S.A.

Alston, J. M., Pardey, P. G., and Smith, V. S. 1998b. Financing agricultural R\&D in rich countries: What's happening and why. Aust. J. Agric. Resour. Econ. 42:51-82.

Bandara, A. Y., Weerasooriya, D. K., Bradley, C. A., Allen, T. W., and Esker, P. D. 2020. Dissecting the economic impact of soybean diseases in the United States over two decades. PLoS One 15:e0231141.

Bayer Crop Science. 2016. ILeVO fungicide label. https://agriculture.basf.us/ content/dam/cxm/agriculture/crop-protection/products/documents/ILeVO_ Label1p.pdf

Bayer Crop Science. 2017. Expanding SDS threat in soybeans in a growing concern. https://dtnpf-digital.com/publication/index.php?i=368510\&m=\&l= $\& \mathrm{p}=79 \& \mathrm{pre}=\&$ ver $=$ html5

Brar, H. K. B., and Bhattacharyya, M. K. 2012. Expression of a single-chain variable-fragment antibody against a Fusarium virguliforme toxin peptide enhances tolerance to sudden death syndrome in transgenic soybean plants. Mol. Plant-Microbe Interact. 25:817-824.

Chong, S. K., Hildebrand, K. K., Luo, Y., Myers, O., Indorante, S. J., Kazakevicius, A., and Russin, J. 2005. Mapping soybean sudden death syndrome as related to yield and soil/site properties. Soil Tillage Res. 84: 101-107.

Crop Protection Network. 2016. Soybean disease loss estimates from the United States and Ontario, Canada-2015. Soybean Disease Management CPN-101815.

Douglas, M. R., and Tooker, J. F. 2015. Large-scale deployment of seed treatments has driven rapid increase in use of neonicotinoid insecticides and preemptive pest management in field crops. Environ. Sci. Technol. 49:5088-5097.

Fernandez-Cornejo, J., Beach, E. D., and Huang, W. Y. 1994. The adoption of IPM techniques by vegetable growers in Florida, Michigan and Texas. J. Agric. Appl. Econ. 26:158-172.

Gaspar, A. P., Mueller, D. S., Wise, K. A., Chilvers, M. I., Tenuta, A. U., and Conley, S. P. 2017. Response of broad-spectrum and target-specific seed treatments and seeding rate on soybean seed yield, profitability, and economic risk. Crop Sci. 57:2251-2262.

Greene, C. R., Kramer, R. A., Norton, G. W., Rajotte, E. G., and Robert, M. M. 1985. An economic analysis of soybean integrated pest management. Am. J. Agric. Econ. 67:567-572.

Haile, M. G., Kalkuhl, M., and von Braun, J. 2015. Worldwide acreage and yield response to international price change and volatility: a dynamic panel data analysis for wheat, rice, corn and soybean. Am. J. Agr. Econ. 98:172-190.

Hershman, D. E. 2003. Soybean diseases control series: Are we missing opportunities? Part 2: Soybean sudden death syndrome. In: Kentucky Pest News PPFS-AG-S-14. http://www.uky.edu/Ag/kpn/kpn_02/pn020311.htm\#soybeans

Jin, H., Hartman, G. L., Nickell, D., and Widholm, J. M. 1996. Phytotoxicity of culture filtrate from Fusarium solani, the causal agent of sudden death syndrome of soybean. Plant Dis. 80:922-927.
Johansson, R. C., Livingston, M. J., Westra, J., and Guidry, K. 2006. Simulating the U.S. impacts of alternative Asian soybean rust treatment regimes. Agric. Resour. Econ. Rev. 35:116-227.

Kandel, Y. R., Bradley, C. A., Chilvers, M. I., Mathew, F. M., Tenuta, A. U., Smith, D. L., Wise, K. A., and Mueller, D. S. 2019a. Effect of seed treatment and foliar crop protection products on sudden death syndrome and yield of soybean. Plant Dis. 103:1712-1720.

Kandel, Y. R., Leandro, L. F. S., and Mueller, D. S. 2019b. Effect of tillage and cultivar on plant population, sudden death syndrome, and yield of soybean in Iowa. Plant Health Prog. 20:29-34.

Kandel, Y. R., McCarville, M. T., Adee, E. A., Bond, J. P., Chilvers, M. I., Conley, S. P., Giesler, L. J., Kelly, H. M., Malvick, D. K., Mathew, F. M., Rupe, J. C., Sweets, L. E., Tenuta, A. U., Wise, K. A., and Mueller, D. S. 2018a. Benefits and profitability of fluopyram-amended seed treatments for suppressing sudden death syndrome and protecting soybean yield: A meta-analysis. Plant Dis. 102:1093-1100.

Kandel, Y. R., Mueller, D. S., Legleiter, T., Johnson, W. G., Young, B. G., and Wise, K. A. 2018b. Impact of fluopyram fungicide and preemergence herbicides on soybean injury, population, sudden death syndrome, and yield. Crop Prot. 106:103-109.

Kandel, Y. R., Wise, K. A., Bradley, C. A., Chilvers, M. I., Tenuta, A. U., and Mueller, D. S. 2016. Fungicide and cultivar effects on sudden death syndrome and yield of soybean. Plant Dis. 100:1339-1350.

Kim, H., and Moschini, G. C. 2018. The Dynamics of Supply: U.S. Corn and Soybeans in the Biofuel Era. Publication 18-wp579. Center for Agricultural and Rural Development (CARD), Iowa State University, Ames, IA. https:// econpapers.repec.org/RePEc:ias:cpaper:18-wp579

Koenning, S. R., and Wrather, J. A. 2010. Suppression of soybean yield potential in the continental united states by plant diseases from 2006 to 2009. Plant Health Prog. 11.

Leandro, L. F. S., Eggenberger, S., Chen, C., Williams, J., Beattie, G. A., and Liebman, M. 2018. Cropping system diversification reduces severity and incidence of soybean sudden death syndrome caused by Fusarium virguliforme. Plant Dis. 102:1748-1758.

Leandro., L. F. S., Robertson, A., Mueller, D. S., Yang, X.-B. 2013. Climatic and environmental trends observed during epidemic and non-epidemic years of soybean sudden death syndrome in Iowa. Plant Health Prog. 14.

Lybbert, T. J., Smith, A. A., and Sumner, D. A. 2014. Weather shocks and interhemispheric supply responses: implications for climate change effects on global food markets. Climate Change Econ. 5:14500010.

Masuda, T., and Goldsmith, P. D. 2009. World soybean demand: an elasticity analysis and long-term projections. Applied Econ Assoc. Annual Meeting, July 26-28, 2009, Milwaukee, WI.

Musser, W. N., Tew, B. V., and Epperson, J. E. 1981. An economic examination of an integrated pest management production system with a contrast between E-V and stochastic dominance analysis. J. Agric. Appl. Econ. 13:119-124

Myers, C., and Hill, E. 2014. Benefits of neonicotinoid seed treatments to soybean production. Office of Chemical and Pollution Prevention, United States Environmental Protection Agency. https://www.epa.gov/sites/production/ files/2014-10/documents/benefits_of_neonicotinoid_seed_treatments_to_ soybean_production_2.pdf

Navi, S. S., and Yang, X. B. 2016. Sudden death syndrome-A growing threat of losses in soybeans. CAB Review, CABI, Wallingford, U.K.

Nettles, R., Watkins, J., Ricks, K., Boyer, M., Licht, M., Atwood, L. W., Peoples, M., Smith, R. G., Mortensen, D. A., and Koide, R. T. 2016. Influence of pesticide seed treatments on rhizosphere fungal and bacterial communities and leaf fungal endophyte communities in maize and soybean. Appl. Soil Ecol. 102:61-69.

Njiti, V. N., Shenaut, M. A., Suttner, R. J., Schmidt, M. E., and Gibson, P. T. 1996. Soybean response to sudden death syndrome: Inheritance influenced by cyst nematode resistance in Pyramid $\times$ Douglas progenies. Crop Sci. 36: 1165-1170.

Norton, G. W., and Mullen, J. 1994. Economic evaluation of the integrated pest management programs: A literature review. Va. Coop. Ext. Publ. 448-120. Virginia Tech, Blacksburg, VA, U.S.A.

O'Donnell, K., Sink, S., Mercedes Scandiani, M., Luque, A., Colletto, A., Biasoli, M., Lenzi, L., Salas, L., González, V., Ploper, L. D., Formento, N., Pioli, R. N., Aoki, T., Yang, X. B., and Sarver, B. A. J. 2010. Soybean sudden death syndrome species diversity within North and South America revealed by multilocus genotyping. Phytopathology 100:58-71.

O'Donoghue, E., Hansen, J., and Stallings, D. 2019. USDA Agricultural Projections to 2028. USDA Agricultural Projections No. OCE-2019-1. Economic Research Service, United States Department of Agriculture https://www.ers.usda.gov/publications/pub-details/?pubid=92599

Reimer, J. J., Zheng, X., and Gehlhar, M. J. 2012. Export demand elasticity estimation for major U.S. crops. J. Agr. Applied Econ. 44:501-515.

Rossman, D. R., Byrne, A. M., and Chilvers, M. I. 2018. Profitability and efficacy of soybean seed treatment in Michigan. Crop Prot. 114:44-52.

Roy, K. W., Rupe, J. C., Hershman, D. E., and Abney, T. S. 1997. Sudden death syndrome of soybean. Plant Dis. 81:1100-1111.

Rupe, J. C. 1989. Frequency and pathogenicity of Fusarium solani recovered from soybeans with sudden death syndrome. Plant Dis. 73:581-584. 
Santísima-Trinidad, A. B. L., del Mar Montiel-Rozas, M., Diéz-Rojo, M. Á., Pascual, J. A., and Ros, M. 2018. Impact of foliar fungicides on target and non-target soil microbial communities in cucumber crops. Ecotoxicol. Environ. Saf. 166:78-85.

Scherm, H., and Yang, X. B. 1999. Risk assessment for sudden death syndrome of soybean in the north-central United States. Agric. Syst. 59:301-310.

Schulz, T., Thelen, K., and Difonzo, C. 2007. Neonicotinoid seed treatments for soybeans. Michigan State Extension. https://www.canr.msu.edu/news/neonicotinoid_ seed_treatments_for_soybeans

Song, F., and Swinton, S. M. 2009. Returns to integrated pest management research and outreach for soybean aphid. J. Econ. Ent. 102:2116-2125.

Stern, V. M., Smith, R. F., van den Bosch, R., and Hagen, K. S. 1959. The integration of chemical and biological control of the spotted alfalfa aphid: The integrated control concept. Hilgardia 29:81-101.

Syngenta. 2019. Be prepared for soybean sudden death syndrome in 2019. Know More Grow More. https://knowmoregrowmore.com/be-prepared-for-soybeansudden-death-syndrome-in-2019/

United Soybean Board. 2017. Soybean disease loss estimates report 2011. https:// www.unitedsoybean.org/wp-content/uploads/Soybean-Disease-Loss-EstimatesReport-2011.xlsx

United Soybean Board. 2019. National soybean checkoff research database. https://www.soybeanresearchdata.com/

USDA-ERS. 2019. Commodity costs and returns. United States Department of Agriculture-Economic Research Service. https://www.ers.usda.gov/data-products/ commodity-costs-and-returns/
USDA-NASS. 2017. Census of Agriculture. United States Department of Agriculture-National Agricultural Statistics Service. https://www.nass.usda.gov/ AgCensus

Vick, C. M., Bond, J. P., Chong, S. K., and Russin, J. S. 2006. Response of soybean sudden death syndrome to tillage and cultivar. Can. J. Plant Pathol. 28:77-83.

Von Qualen, R. H., Abney, T. S., Huber, D. M., and Schreiber, M. M. 1989. Effects of rotation, tillage, and fumigation on premature dying of soybeans. Plant Dis. 73:740-744.

Wang, S. L., Heisey, P. W., Huffman, W. E., and Fuglie, K. O. 2013. Public R\&D and U.S. agricultural productivity growth: Dynamic and long-run relationships. Am. J. Agric. Econ. 95:1287-1293.

Ward, B., Lindsey, L., and Loux, M. 2018. Soybean production budget (RoundUp ready)-2019. Farm Office, Ohio State University. https://farmoffice.osu.edu/ farm-mgt-tools/farm-budgets

Xing, L., and Westphal, A. 2006. Interaction of Fusarium solani f. sp. glycines and Heterodera glycines in sudden death syndrome of soybean. Phytopathology 96: 763-770.

Xing, L., and Westphal, A. 2009. Effects of crop rotation of soybean with corn on severity of sudden death syndrome and population densities of Heterodera glycines in naturally infested soil. Field Crops Res. 112:107-117.

Zilberman, D., Sexton, S. E., Marra, M., and Fernandez-Cornejo, J. 2010. The economic impact of genetically engineered crops. Choices 25(2). https:// naldc.nal.usda.gov/download/44203/PDF 